\title{
Amphibacillus sediminis sp. nov., an endospore- forming bacterium isolated from lake sediment in Japan
}

\author{
Sun-Young An, ${ }^{1}$ Shu Ishikawa, ${ }^{2}$ Hiroaki Kasai, ${ }^{2}$ Keiichi Goto ${ }^{3}$ \\ and Akira Yokota ${ }^{1}$
}

Correspondence

Sun-Young An

an12su@hotmail.com

\author{
${ }^{1}$ Institute of Molecular and Cellular Biosciences, The University of Tokyo, Yayoi, 1-1-1, Bunkyo-Ku, \\ Tokyo 113-0032, Japan \\ ${ }^{2}$ Marine Biotechnology Institute Co. Ltd, 3-75-1, Heita, Kamaishi, Iwate 026-0001, Japan \\ ${ }^{3}$ Microbiological and Analytical Group, Food Research Laboratories, Mitsui Norin Co. Ltd, 223-1, \\ Miyahara, Fujieda, Shizuoka 426-0133, Japan
}

The genus Amphibacillus was first proposed by Niimura et al. (1990) and the genus currently comprises three recognized species, Amphibacillus xylanus (Niimura et al., 1990), Amphibacillus fermentum and Amphibacillus tropicus (Zhilina et al., 2001). Members of the genus Amphibacillus are moderately alkaliphilic and facultatively anaerobic (Zhilina et al., 2001) and lack isoprenoid quinones and oxidase activity (Niimura et al., 1990).

Here, we describe a novel strain, Shu-P-Ggiii25-2 $2^{\mathrm{T}}$, which was isolated from sediment from Lake Hamana (Shizuoka, Japan) in the course of an environmental investigation. Based on partial 16S rRNA gene sequence analyses, the novel strain was found to be closely related to the genus Amphibacillus. The aim of the present study is to elucidate the taxonomic position of the isolate by using a polyphasic approach (physiological and chemotaxonomical analyses, fatty acid composition, quinone system, DNA G+C content and 16S rRNA gene sequence analysis). Based on

Abbreviation: BTB, bromothymol blue.

The GenBank/EMBL/DDBJ accession number for the 16S rRNA gene sequence of strain Shu-P-Ggiii25-2 ${ }^{\top}$ is AB243866. these substantial data, it is proposed that the isolate represents a novel species in the genus Amphibacillus.

Strain Shu-P-Ggiii25-2 ${ }^{\mathrm{T}}$ was isolated from sediment at a depth of $1 \mathrm{~m}$ in Lake Hamana in Shizuoka, Japan, in 2004. Suspended sediment was used for enrichment culture using GYPiii medium [5 $\mathrm{g}$ Bacto yeast extract (BD), $1 \mathrm{~g}$ Polypepton (soybean, Nihon Pharma), $1 \mathrm{~g}$ casein Polypepton (Nihon Pharma), $1 \mathrm{~g}$ fish meat extract, $2 \mathrm{~g}$ $\mathrm{CaCO}_{3}, 1.5 \mathrm{~g} \mathrm{Na}_{2} \mathrm{CO}_{3}, 10 \mathrm{~g}$ glucose, $70 \mathrm{~g} \mathrm{NaCl}, 1 \mathrm{mg}$ sodium pyruvate, $20 \mathrm{mg} \quad \mathrm{MgSO}_{4} \cdot 7 \mathrm{H}_{2} \mathrm{O}, 1 \mathrm{mg}$ $\mathrm{MnSO}_{4} .4 \mathrm{H}_{2} \mathrm{O}, 1 \mathrm{mg} \mathrm{FeSO}_{4} .7 \mathrm{H}_{2} \mathrm{O}, 10 \mathrm{mg}$ colistin, $10 \mathrm{mg}$ sodium azide, $10 \mathrm{mg}$ cycloheximide, $30 \mathrm{mg}$ bromothymol blue (BTB), $5 \mathrm{mg}$ Tween $80,900 \mathrm{ml}$ seawater for 11 medium, pH 10] after incubation at $25{ }^{\circ} \mathrm{C}$. When the colour of the $\mathrm{pH}$ indicator, $\mathrm{BTB}$, changed, a small portion of culture was transferred to new medium. Strain Shu-P-Ggiii25-2 ${ }^{\mathrm{T}}$ was isolated from the second enrichment culture on GYPiii agar after incubation at $25{ }^{\circ} \mathrm{C}$ for three days. Isolate Shu-PGgiii25-2 ${ }^{\mathrm{T}}$ was routinely cultivated on trypticase soy agar (TSA; BBL) containing $50 \%$ Herbst's artificial seawater and incubated at $27{ }^{\circ} \mathrm{C}$. Herbst's artificial seawater contains the following $\left(\mathrm{l}^{-1}\right.$ distilled water): $30 \mathrm{~g} \mathrm{NaCl}, 0.7 \mathrm{~g} \mathrm{KCl}, 5.3 \mathrm{~g}$ $\mathrm{MgSO}_{4} \cdot 7 \mathrm{H}_{2} \mathrm{O}, 1.3 \mathrm{~g} \mathrm{CaCl}_{2} \cdot 2 \mathrm{H}_{2} \mathrm{O}$ and $10.8 \mathrm{~g} \mathrm{MgCl}_{2} \cdot 6 \mathrm{H}_{2} \mathrm{O}$. 
Cell morphology and motility were examined using phasecontrast microscopy (BX60; Olympus). Growth under anaerobic conditions was determined after a week of incubation in an AnaeroPack (Mitsubishi Gas Chemical Co., Ltd). The temperature range for growth was assessed at various temperatures $\left(5-60{ }^{\circ} \mathrm{C}\right)$. The $\mathrm{pH}$ range for growth was determined by adjusting the medium to various $\mathrm{pH}$ values (initial $\mathrm{pH} 6.0-10.0$ at intervals of $0.5 \mathrm{pH}$ units). Prior to sterilization, the $\mathrm{pH}$ was adjusted to various levels by using $\mathrm{HCl}$ and $\mathrm{NaOH}$. Growth at various $\mathrm{NaCl}$ concentrations was investigated in trypticase soy agar containing $50 \%$ Herbst's artificial seawater lacking $\mathrm{NaCl}$. Catalase activity was tested by adding a drop of $3 \% \mathrm{H}_{2} \mathrm{O}_{2}$ to a single colony and was recorded as positive when the development of bubbles was observed. Oxidase activity was determined by cytochrome oxidase paper (Nissui Pharmaceutical Co., Ltd). API 20E and API 50CH microtest galleries (bioMérieux) were used according to the manufacturer's instructions to determine the physiological and biochemical characteristics of the novel strain. The API strips were recorded after 2 days of incubation at $30{ }^{\circ} \mathrm{C}$. The results of the morphological, biochemical and physiological properties are given in the species description.

Based on a comparison of partial 16S rRNA gene sequences (Goto et al. 2000, 2002), strain Shu-P-Ggiii25-2 ${ }^{\mathrm{T}}$ was placed in the Amphibacillus-Halolactobacillus cluster. However, the sequences of the novel strain were found to be distinct from previously described species of both of these genera. The 16S rRNA gene sequence was determined using a 16S rRNA gene kit following the manufacturer's protocols (Applied Biosystems). The 16S rRNA gene sequence of strain Shu-P-Ggiii25-2 ${ }^{\mathrm{T}}$ was used for BLAST searches via the NCBI (National Center for Biotechnology Information). The sequences obtained were aligned by using the CLUSTAL_X software package (Thompson et al., 1997 ) and evolutionary distances and $K_{\text {nuc }}$ values (Kimura, 1980) were generated. Alignment gaps and ambiguous bases were not considered when the 1350 bases of the $16 \mathrm{~S}$
rRNA gene were compared. A phylogenetic tree was constructed using the neighbour-joining method (Saitou \& Nei, 1987). The topology of the phylogenetic tree was evaluated by the bootstrap resampling method of Felsenstein (1985) with 1000 replicates. The similarity values were calculated using MEGA3 (Kumar et al., 2004). The almost complete 16S rRNA gene sequence of strain Shu-P-Ggiii25-2 $2^{\mathrm{T}}$ was determined and subjected to comparative analysis. The highest degree of 16S rRNA gene sequence similarity was found with Paraliobacillus ryukyuensis $(96.0 \%)$, followed by that with Amphibacillus tropicus (95.6\%), Halolactibacillus miurensis (95.2\%), Halolactibacillus halophilus (95.1\%), Amphibacillus fermentum (94.9\%) and Amphibacillus xylanus (94.9\%). The phylogenetic tree shown in Fig. 1 indicates that strain ShuP-Ggiii $25-2^{\mathrm{T}}$ is closely related to the genus Amphibacillus.

Genomic DNA was prepared according to the method of Marmur (1961) and the DNA G + C content was measured by HPLC as described by Mesbah et al. (1989). The cellular fatty acids were identified with the Sherlock Microbial Identification System (MIDI) and strain Shu-P-Ggiii25-2 ${ }^{\mathrm{T}}$ and the type species of the genus Amphibacillus were incubated on DSM 529 medium (DSM online catalogue; http://www.dsmz.de/) for 3 days at $30{ }^{\circ} \mathrm{C}$. The analysis of cell-wall peptidoglycan was performed according to the methods of Schleifer \& Kandler (1972). Respiratory quinone analyses were performed by using the method described by Collins \& Jones (1981).

The DNA G + C content of strain Shu-P-Ggiii25-2 ${ }^{\mathrm{T}}$ was $42.3 \mathrm{~mol} \%$. The major fatty acid of strain Shu-P-Ggiii $25-2^{\mathrm{T}}$ was iso- $\mathrm{C}_{14: 0}(18.2 \%)$, iso- $\mathrm{C}_{15: 0}(17.9 \%)$, anteiso- $\mathrm{C}_{15: 0}$ $(17.8 \%), \mathrm{C}_{16: 0}(14.1 \%)$ and iso- $\mathrm{C}_{16: 0}(9.2 \%)$. This fatty acid profile is quite similar to those of the other recognized species of the genus Amphibacillus (Table 1). Strain Shu-PGgiii25-2 $2^{\mathrm{T}}$ possessed cell-wall peptidoglycans based on meso-diaminopimelic acid, which is the same type as the phylogenetically closely related neighbours Amphibacillus xylanus and Amphibacillus tropicus (Fig. 1). Isoprenoid

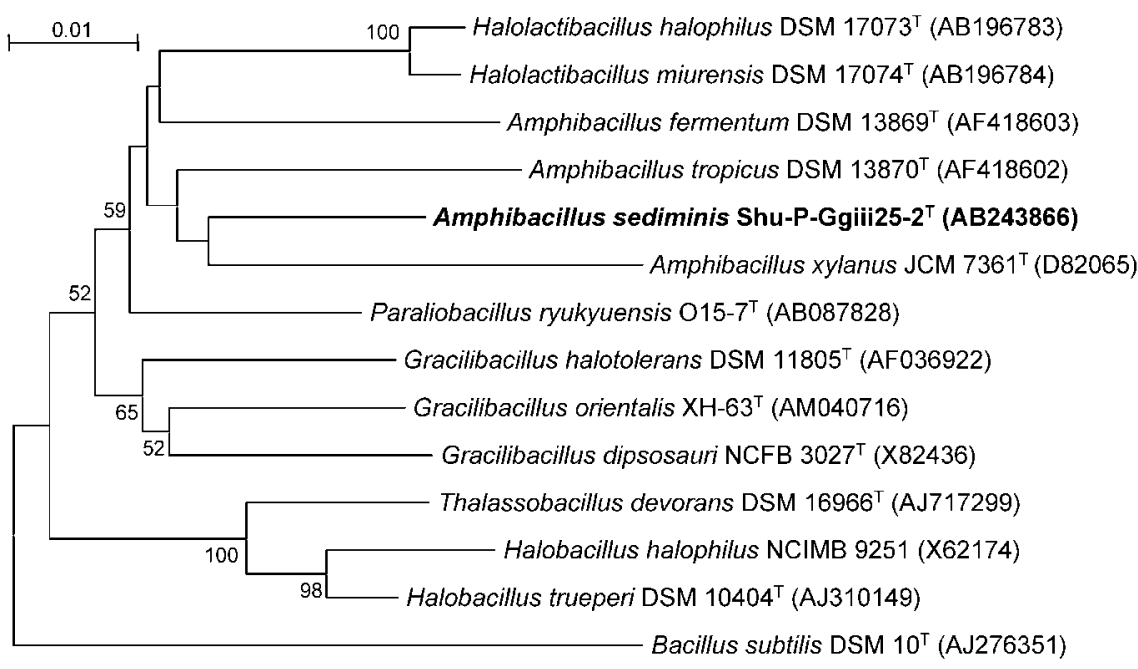

Fig. 1. Neighbour-joining phylogenetic tree based on 16S rRNA gene sequences showing the positions of strain Shu-P-Ggiii $25-2^{\top}$ and other related taxa. Numbers at the nodes indicate the percentages of occurrence in 1000 bootstrapped trees; only values $>50 \%$ are shown. Bar, 1 substitution per 100 nucleotides. 
Table 1. Fatty acid content of Amphibacillus sediminis sp. nov. and related organisms

Taxa: 1, A. sediminis sp. nov.; 2, A. xylanus; 3, A. fermentum; 4, A. tropicus; 5, H. halophilus (Ishikawa et al., 2005); 6, H. miurensis (Ishikawa et al., 2005). Fatty acids representing $<1 \%$ are not shown.

\begin{tabular}{|c|c|c|c|c|c|c|}
\hline Fatty acid & 1 & 2 & 3 & 4 & 5 & 6 \\
\hline $\mathrm{C}_{12: 0}$ & & & 2.4 & 4.3 & 2.5 & 2.1 \\
\hline $\mathrm{C}_{14: 0}$ & 16.3 & 15.0 & 25.9 & 9.6 & 4.1 & 4.0 \\
\hline $\mathrm{C}_{15: 0}$ & 1.2 & 1.5 & & 5.8 & 1.4 & 1.6 \\
\hline $\mathrm{C}_{16: 0}$ & 14.1 & 15.0 & 22.9 & 31.4 & 43.1 & 37.2 \\
\hline $\mathrm{C}_{16: 1}$ & & & & & & 1.3 \\
\hline $\mathrm{C}_{18: 0}$ & & & & & 4.6 & 5.5 \\
\hline $\mathrm{C}_{18: 1 \Delta 9}$ & & & & & 2.7 & 2.2 \\
\hline $\mathrm{C}_{18: 2}$ & & & & & 1.1 & 1.2 \\
\hline iso- $\mathrm{C}_{13: 0}$ & 2.1 & 1.8 & 4.9 & & 6.5 & 5.7 \\
\hline anteiso- $\mathrm{C}_{13: 0}$ & & 2.0 & 9.6 & 3.5 & 19.1 & 18.8 \\
\hline iso- $\mathrm{C}_{14: 0}$ & 18.2 & 9.7 & 3.9 & 7.3 & & \\
\hline iso- $\mathrm{C}_{15: 0}$ & 17.9 & 10.3 & 5.8 & 7.8 & 3.5 & 3.7 \\
\hline anteiso- $\mathrm{C}_{15: 0}$ & 17.8 & 28.2 & 18.7 & 22.1 & 6.2 & 7.6 \\
\hline iso- $\mathrm{C}_{16: 0}$ & 9.2 & 10.8 & 1.0 & 3.8 & & \\
\hline iso- $\mathrm{C}_{17: 0}$ & & & & & 1.5 & 3.5 \\
\hline anteiso- $\mathrm{C}_{17: 0}$ & 1.5 & 4.1 & 1.0 & 1.1 & & 2.5 \\
\hline
\end{tabular}

quinones were not detected for the novel strain, as is also the case for the type species of the genera Amphibacillus (Niimura et al., 1990; Zhilina et al., 2001) and Halolactibacillus (Ishikawa et al., 2005).

The chemotaxonomic characteristics of strain Shu-PGgiii25- $2^{\mathrm{T}}$ are consistent with those of the type species of the genus Amphibacillus, i.e. lacking quinones and cytochromes, and the novel strain exhibited similar cellular fatty acid contents (Tables 1 and 2). In addition, strain Shu-P-Ggiii25-2 ${ }^{\mathrm{T}}$ can be clearly distinguished from Paraliobacillus ryukyuensis by its lack of quinones, even though they share a high 16S rRNA gene sequence similarity. When compared with another neighbouring genus, Halolactibacillus, strain Shu-P-Ggiii25-2 $2^{\mathrm{T}}$ could be differentiated from the type species of this genus by its high content of the fatty acids $\mathrm{C}_{14: 0}$, iso- $\mathrm{C}_{14: 0}$, iso- $\mathrm{C}_{15: 0}$ and anteiso- $\mathrm{C}_{15: 0}$ and relatively low content of fatty acids $\mathrm{C}_{16: 0}$ and anteiso- $\mathrm{C}_{13: 0}$ (Table 1). On the basis of phylogenetic analysis and physiological and chemotaxonomical characteristics, we conclude that strain Shu-P-Ggiii25-2 $2^{\mathrm{T}}$ represents a novel species of the genus Amphibacillus, for which the name Amphibacillus sediminis sp. nov. is proposed. An emended description of the genus Amphibacillus is given to reflect the moderately alkaliphilic and less biochemically reactive nature of Amphibacillus sediminis sp. nov.

\section{Emended description of the genus Amphibacillus Niimura et al. 1990}

Amphibacillus (Am.phi.ba.cil'lus. Gr. pref. amphi both sides or double; L. dim. n. bacillus a small rod; N.L. masc. n. Amphibacillus rod capable of both aerobic and anaerobic growth).

The description is based on that given by Niimura et al. (1990) with the following additions. Cells are Grampositive, moderately alkaliphilic, facultatively anaerobic rods. Catalase activity is variable. The $\mathrm{G}+\mathrm{C}$ content of the genomic DNA is $36-42 \mathrm{~mol} \%$. The type species of the genus is Amphibacillus xylanus.

\section{Description of Amphibacillus sediminis sp. nov.}

Amphibacillus sediminis (sed.i.mi' nis. L. gen. n. sediminis of a sediment).

Cells are Gram-positive long rods that are facultatively anaerobic and non-motile. Spherical endospores are formed in the terminal position. Colonies grown on trypticase soy agar containing $50 \%$ Herbst's artificial seawater are circular, convex and white. The optimal temperature for growth is $27{ }^{\circ} \mathrm{C}$; growth occurs at 17 $55{ }^{\circ} \mathrm{C}$, but not at $10{ }^{\circ} \mathrm{C}$ or $60{ }^{\circ} \mathrm{C}$. Optimal $\mathrm{pH}$ for growth is 8.5; growth occurs at $\mathrm{pH} 7.0-9.0$, but not at $\mathrm{pH} 6.5$ or $\mathrm{pH}$ 9.5. $\mathrm{NaCl}$ is not required for growth but can be tolerated at concentrations of up to $6 \% \mathrm{NaCl}(\mathrm{w} / \mathrm{v})$. Catalase and oxidase activities are negative. Acetoin is produced. $\mathrm{H}_{2} \mathrm{~S}$ and indole are not produced. Nitrate is not

Table 2. Differential characteristics of Amphibacillus sediminis sp. nov. and related organisms

1, A. sediminis sp. nov.; 2, A. xylanus (data from Niimura et al., 1990); 3, A. fermentum (Zhilina et al., 2001); 4, A. tropicus (Zhilina et al., 2001); 5, H. halophilus (Ishikawa et al., 2005); 6, H. miurensis (Ishikawa et al., 2005); 7. P. ryukyuensis (Ishikawa et al., 2002). +, Positive; -, negative.




reduced. Urease, gelatinase, $\beta$-galactosidase and arginine dihydrolase activities are positive. Lysine decarboxylase, ornithine decarboxylase and tryptophan deaminase activities and utilization of citrate are negative. Acid is produced from glycerol, glucose, fructose, mannose, aesculin, maltose and sucrose, but not from erythritol, D-arabinose, $\mathrm{L}$-arabinose, ribose, D-xylose, L-xylose, adonitol, methyl $\beta$ D-xyloside, galactose, sorbose, rhamnose, dulcitol, inositol, mannitol, sorbitol, methyl $\alpha$-D-mannoside, methyl $\alpha$-Dglucoside, $N$-acetylglucosamine, amygdalin, arbutin, salicin, cellobiose, lactose, melibiose, trehalose, inulin, melezitose, raffinose, starch, glycogen, xylitol, gentiobiose, D-turanose, D-lyxose, D-tagatose, D-fucose, L-fucose, D-arabitol, L-arabitol, gluconate, 2-keto-gluconate or 5keto-gluconate. Cell walls contain peptidoglycans of the meso-diaminopimelic acid type. Isoprenoid quinones are not detected. The major cellular fatty acids are iso- $\mathrm{C}_{14: 0}$, iso- $\mathrm{C}_{15: 0}$, anteiso- $\mathrm{C}_{15: 0}, \mathrm{C}_{16: 0}$ and iso- $\mathrm{C}_{16: 0}$. The genomic DNA $\mathrm{G}+\mathrm{C}$ content of the type strain is $42.3 \mathrm{~mol} \%$.

The type strain, Shu-P-Ggiii25- $2^{\mathrm{T}}\left(=\mathrm{MBIC} 08269^{\mathrm{T}}=\mathrm{IAM}\right.$ $15428^{\mathrm{T}}=$ KCTC $13120^{\mathrm{T}}$ ), was isolated from sediment from Lake Hamana (Shizuoka, Japan).

\section{Acknowledgements}

We thank Chiaki Komukai, Atsuko Katsuta and Ayako Matsuzaki for their technical assistance. Part of this work was supported by New Energy and Industrial Technology Development Organization (NEDO).

\section{References}

Collins, M. D. \& Jones, D. (1981). Distribution of isoprenoid quinone structural types in bacteria and their taxonomic implications. Microbiol Rev 45, 316-354.

Felsenstein, J. (1985). Confidence limits on phylogenies: an approach using the bootstrap. Evolution 39, 783-791.

Goto, K., Omura, T., Hara, Y. \& Sadaie, Y. (2000). Application of the partial $16 \mathrm{~S}$ rDNA sequence as an index for rapid identification of species in the genus Bacillus. J Gen Appl Microbiol 46, 1-8.

Goto, K., Mochida, K. M., Asahara, M., Suzuki, M. \& Yokota, A. (2002). Application of the hypervariable region of the $16 \mathrm{~S}$ rDNA sequence as an index for the rapid identification of species in the genus Alicyclobacillus. J Gen Appl Microbiol 48, 243-250.

Ishikawa, M., Ishizaki, S., Yamamoto, Y. \& Yamasato, K. (2002). Paraliobacillus ryukyuensis gen. nov., sp. nov., a new Gram-positive, slightly halophilic, extremely halotolerant, facultative anaerobe isolated from a decomposing marine alga. J Gen Appl Microbiol 48, 269-279.

Ishikawa, M., Nakajima, K., Itamiya, Y., Furukawa, S., Yamamoto, Y. \& Yamasato, K. (2005). Halolactibacillus halophilus gen. nov., sp. nov. and Halolactibacillus miurensis sp. nov., halophilic and alkaliphilic marine lactic acid bacteria constituting a phylogenetic lineage in Bacillus rRNA group 1. Int J Syst Evol Microbiol 55, 2427-2439.

Kimura, M. (1980). A simple method for estimating evolutionary rates of base substitutions through comparative studies of nucleotide sequences. J Mol Evol 16, 111-120.

Kumar, S., Tamura, K., Jakobsen, I. B. \& Nei, M. (2004). MEGA3: integrated software for molecular evolutionary genetics analysis and sequence alignment. Brief Bioinform 5, 150-163.

Marmur, J. (1961). A procedure for the isolation of deoxyribonucleic acid from microorganisms. J Mol Biol 3, 208-218.

Mesbah, M., Premachandran, U. \& Whitman, W. B. (1989). Precise measurement of the $\mathrm{G}+\mathrm{C}$ content of deoxyribonucleic acid by high-performance liquid chromatography. Int J Syst Bacteriol 39, 159-167.

Niimura, Y., Koh, E., Yanagida, F., Suzuki, K., Komagata, K. \& Kozaki, M. (1990). Amphibacillus xylanus gen. nov., sp. nov., a facultatively anaerobic sporeforming xylan-digesting bacterium which lacks cytochrome, quinone, and catalase. Int J Syst Bacteriol 40, 297-301.

Saitou, N. \& Nei, M. (1987). The neighbor-joining method: a new method for reconstructing phylogenetic trees. Mol Biol Evol 4, 406-425.

Schleifer, K. H. \& Kandler, O. (1972). Peptidoglycan types of bacterial cell walls and their taxonomic implications. Bacteriol Rev 36, 407-477.

Thompson, J. D., Gibson, T. J., Plewniak, F., Jeanmougin, F. \& Higgins, D. G. (1997). The CLUSTAL_X windows interface: flexible strategies for multiple sequence alignment aided by quality analysis tools. Nucleic Acids Res 25, 4876-4882.

Zhilina, T. N., Garnova, E. S., Tourova, T. P., Kostrikina, N. A. \& Zavarzin, G. A. (2001). Amphibacillus fermentum sp. nov. and Amphibacillus tropicus sp. nov., new alkaliphilic, facultatively anaerobic, saccharolytic bacilli from Lake Magadi. Microbiology (English translation of Mikrobiologiia) 70, 711-722. 